\title{
Left atrial to coronary sinus fenestration (partially unroofed coronary sinus) Morphological and angiocardiographic observations
}

\author{
ROBERT M FREEDOM, J A G CULHAM, RICHARD D ROWE
}

From the Division of Cardiology, Department of Paediatrics, Pathology, and Radiology, The Hospital for Sick Children, and Departments of Paediatrics, Pathology, and Radiology, University of Toronto, Faculty of Medicine, Toronto, Canada

SUMMARY The necropsy findings and characteristic angiocardiographic appearance of left atrial to coronary fenestration are presented. This fenestration is probably a forme fruste of the developmental complex previously described of termination of the left superior vena cava in the left atrium, atrial septal defect, and absence of the coronary sinus. The partially unroofed coronary sinus provides an alternate or accessory route for blood flow when the atrium has no other functional exit. The angiocardiographic diagnosis is facilitated by selective injection of contrast material in the left atrium (or pulmonary vein) or left superior vena cava when the cava connects to the coronary sinus and left atrium via the fenestration.

Congenital fenestration between the coronary sinus and left atrium is rare, ${ }^{1-10}$ and when present may provide an alternative or accessory, though vital, route for the flow of blood in the patient with a severely obstructive, absent, or imperforate atrioventricular connection and inadequate interatrial septal communication. ${ }^{2-48-10}$ Sometimes, even less frequently, this unusual form of intracardiac fenestration may be an incidental necropsy finding or associated with an otherwise uncomplicated atrial septal defect. ${ }^{2} 67$

Though the morphological appearance of left atrial to coronary sinus window has been recorded in a few instances, ${ }^{1-10}$ this fenestration is rarely diagnosed during life and we wish, therefore, to present our pathological and angiocardiographic experience with six patients, and to comment on the circulatory and clinical implications of this anomaly.

\section{Subjects}

A communication between the floor of the left atrium and coronary sinus (partially unroofed coronary sinus) was identified in six patients. The sex distribution was equal, and the age at diagnosis ranged from 2 months to 9 years and 7 months. The fenestration was diagnosed only at necropsy in two patients; at operation in one

Received for publication 2 December 1980 patient, who is still alive; and by angiocardiography and confirmed at necropsy in three.

All the patients had laevocardia with situs solitus. Two had obstructive anomalies of the tricuspid valve. A 2-month-old infant had tricuspid atresia, intact atrial septum, ventricular septal defect, and pulmonary stenosis and died after attempted systemic to pulmonary anastomosis. The fenestration was recognised at necropsy. The other patient, a boy aged 9 years and 7 months, had pulmonary atresia, an intact ventricular septum, a diminutive and hypertensive right ventricle, and persistence of the left superior vena cava. The diagnosis of coronary sinus to left atrial window was made by angiocardiography and confirmed at necropsy. The diagnosis was also made angiographically and confirmed at necropsy in two patients with obstructive anomalies of the mitral valve. One had mitral atresia with normal ventriculoarterial connections, and the other, mitral stenosis, Taussig-Bing type double outlet right ventricle, subpulmonary infundibular ventricular septal defect, a small ventricular septal defect, a poorly expanded subaortic infundibulum, thoracic coarctation of the aorta, and an atrial septal defect.

In two cases the sole other intracardiac anomaly was a secundum atrial septal defect. In one of them, a patient who died in 1959 after surgical repair of the atrial defect, the fenestration was recognised only at necropsy. In the other the window was diagnosed in 
Table Hearts associated with left atrial to coronary sinus window

\begin{tabular}{|c|c|c|c|}
\hline Type of heart & No. examined & Status of atrial septum & Comments \\
\hline Mitral atresia with normal aortic root & 1 & Intact & \\
\hline Secundum atrial septal defect & 1 & $2.5 \times 2.5 \mathrm{~cm}$ & $\begin{array}{l}\text { Died after surgery in } 1959, \text { had a paradoxical } \\
\text { embolus }\end{array}$ \\
\hline $\begin{array}{l}\text { Mitral atresia, Taussig-Bing, double outlet } \\
\text { right ventricle, coarctation }\end{array}$ & 2 & Secundum atrial septal defect & \\
\hline $\begin{array}{l}\text { Tricuspid atresia with normal ventriculoarterial } \\
\text { connections and severe pulmonary stenosis }\end{array}$ & 1 & $1.0 \mathrm{~mm}$ fenestration in septum primum & \\
\hline $\begin{array}{l}\text { Pulmonary atresia, intact ventricular septum, } \\
\text { diminutive and hypertensive right ventricle }\end{array}$ & 1 & $4 \times 4 \mathrm{~mm}$ secundum atrial septal defect & $\begin{array}{l}\text { Stenosis of right atrial ostium of coronary sinus; } \\
\text { LSVC to coronary sinus }\end{array}$ \\
\hline Secundum atrial septal defect & 1 & Patch closure $2 \times 1.0 \mathrm{~cm}$ & \\
\hline
\end{tabular}

1979 in a 13-year-old boy undergoing surgical closure of the atrial septal defect. The window was diagnosed intraoperatively (operation performed at The Hospital for Sick Children by Dr W G Williams).

\section{ANATOMY OF CORONARY SINUS AND LEFT}

ATRIAL TO CORONARY SINUS WINDOW

In the five recognised patients (patients 1-5) the coronary sinus occupied its normal position, and no patient had morphological features of the developmental complex described by Raghib and his colleagues in $1965,{ }^{\prime}$ of termination of the left superior vena cava in the left atrium, atrial septal defect, and absence of the coronary sinus.

The fenestration between the coronary sinus and the left atrium was a discrete defect in the posterior wall of the left atrium, above the level of the annular insertion of the posterior mitral leaflet, either a circle (two patients) or elliptical (two patients) (Fig. 1 and 2). When a circle, the diameter of the window averaged 9.0

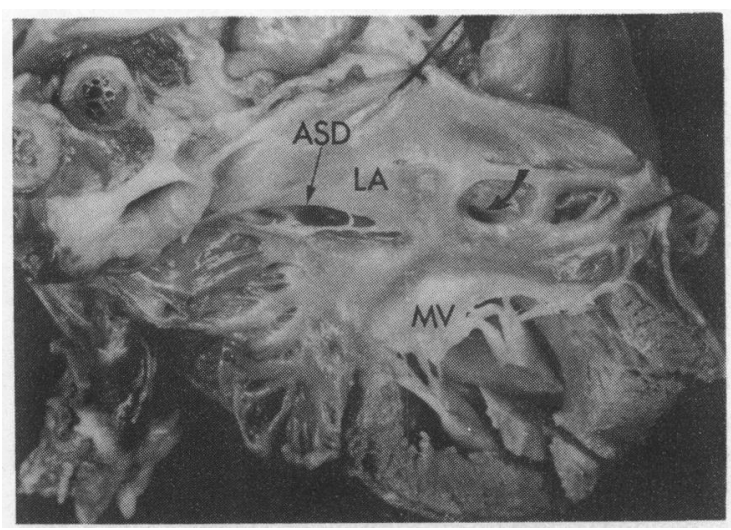

Fig. 1 Internal view of left atrium ( $L A)$ in an infant with Taussig-Bing double outlet right ventricle, a small ventricular septal defect, mild mitral stenosis, and subaortic stenosis. The left atrium $(L A)$ is slightly dilated, and there is a small atrial septal defect (ASD). A fenestration in the left atrium superior to the annulus of the posterior mitral leaflet connects with the coronary sinus (curvilinear arrow).

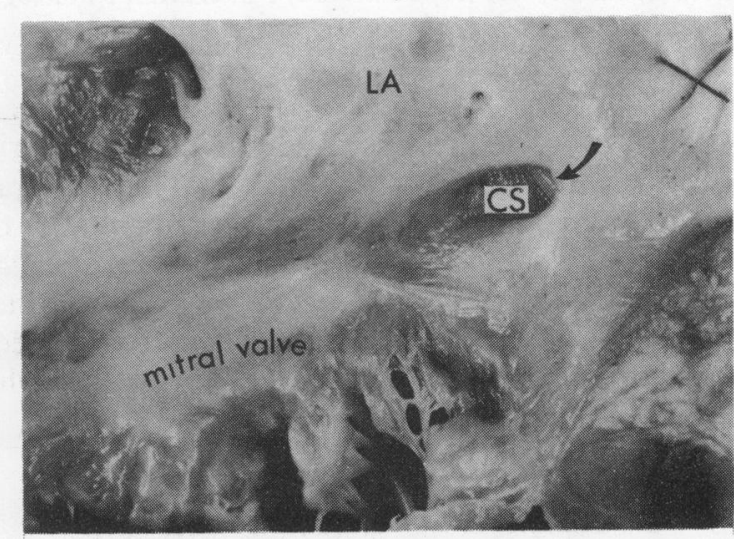

Fig. 2 A boy just under 10 years of age with pulmonary atresia, intact ventricular septum, severe tricuspid stenosis, a diminutive and hypertensive right ventricle, myocardial sinusoidal-coronary artery communications, and a nearly sealed foramen ovale.

Internal view of enlarged left atrium (LA). The mitral valve is well seen. The posterior wall of the left atrium, superior to posterior leaflet of the mitral valve, is fenestrated (curvilinear arrow) and connects to the coronary sinus (CS).

$\mathrm{mm}$, and when elliptical, the dimensions of the long and short axis averaged $12 \times 6 \mathrm{~mm}$, respectively. No patient had multiple fenestrations. ${ }^{2}$ A persistent left superior vena cava was found in one patient at necropsy, and had been found at angiography in another.

The ostium of the coronary sinus appeared of normal calibre in all but one case. This patient, with pulmonary atresia, intact ventricular septum, severe tricuspid stenosis, a diminutive and hypertensive right ventricle, and a $2 \times 3 \mathrm{~mm}$ secundum atrial septal defect, had severe stenosis of the right atrial ostium of the coronary sinus (Fig. 3) and a left superior vena cava connected to the coronary sinus (see Fig. 2 and 6).

\section{ANGIOCARDIOGRAPHIC FINDINGS}

The diagnosis of left atrial to coronary sinus window was made by selective injection of contrast material in the left atrium or pulmonary vein in three patients and 


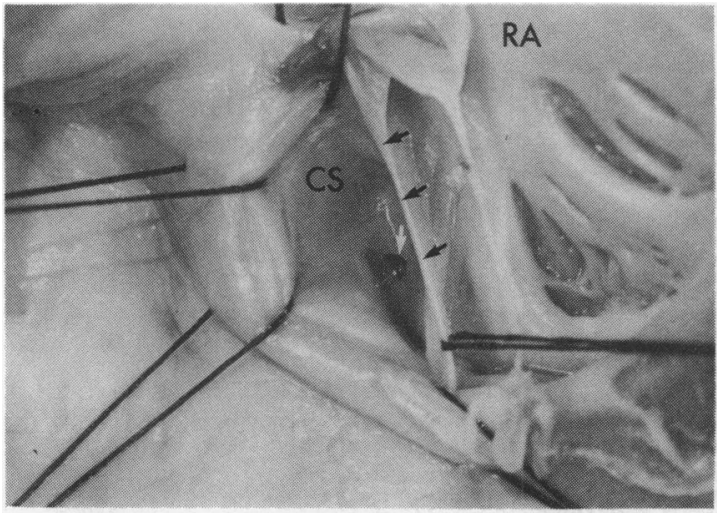

Fig. 3 Same patient as in Fig. 2. Internal view of right atrium (RA) with magnified view of the right atrial ostium of coronary sinus (CS). The valve of the coronary sinus (black arrows) is seen. There is severe stenosis of the ostium of the coronary sinus (white arrow) which would admit only a $2.0 \mathrm{~mm}$ probe.

in a left superior vena cava connecting to both the coronary sinus and the left atrium in one patient.

The left atrium varied considerably in size, from small to moderately enlarged, as in the patient with pulmonary atresia. In one patient with mitral atresia, injection of contrast material into a left pulmonary vein was followed sequentially by opacification of the left atrium and coronary sinus (Fig. 4). The lateral view clearly shows contrast passing posteriorly from the left atrium to the coronary sinus by way of the fenestration between the floor of the left atrium and the roof of coronary sinus (Fig. 4b).

The patient in whom the diagnosis was made by left superior vena cava injection had pulmonary atresia, an intact ventricular septum, and a severely hypertensive right ventricle, and the right atrial mean pressure was 6.0 $\mathrm{mmHg}$ higher than the left atrial mean pressure. Injection of contrast material in the right superior vena cava above the level of the left brachiocephalic vein showed dense opacification of the left brachiocephalic vein, a persistent left superior vena cava, and the left atrium and left ventricle, despite the course of the left superior vena cava which appeared typical of a connection to the coronary sinus (Fig. 5a).

Selective injection in the left superior vena cava in the anteroposterior projection showed dense opacification of the left atrium (Fig. 5). In the lateral view, the contrast material divided into two streams (Fig. 5b), one passing superiorly and the other inferiorly. A little later, the atrial septum was clearly outlined (Fig. 5c). The anatomy in this case was confirmed at necropsy (see Fig. 2 and 3).
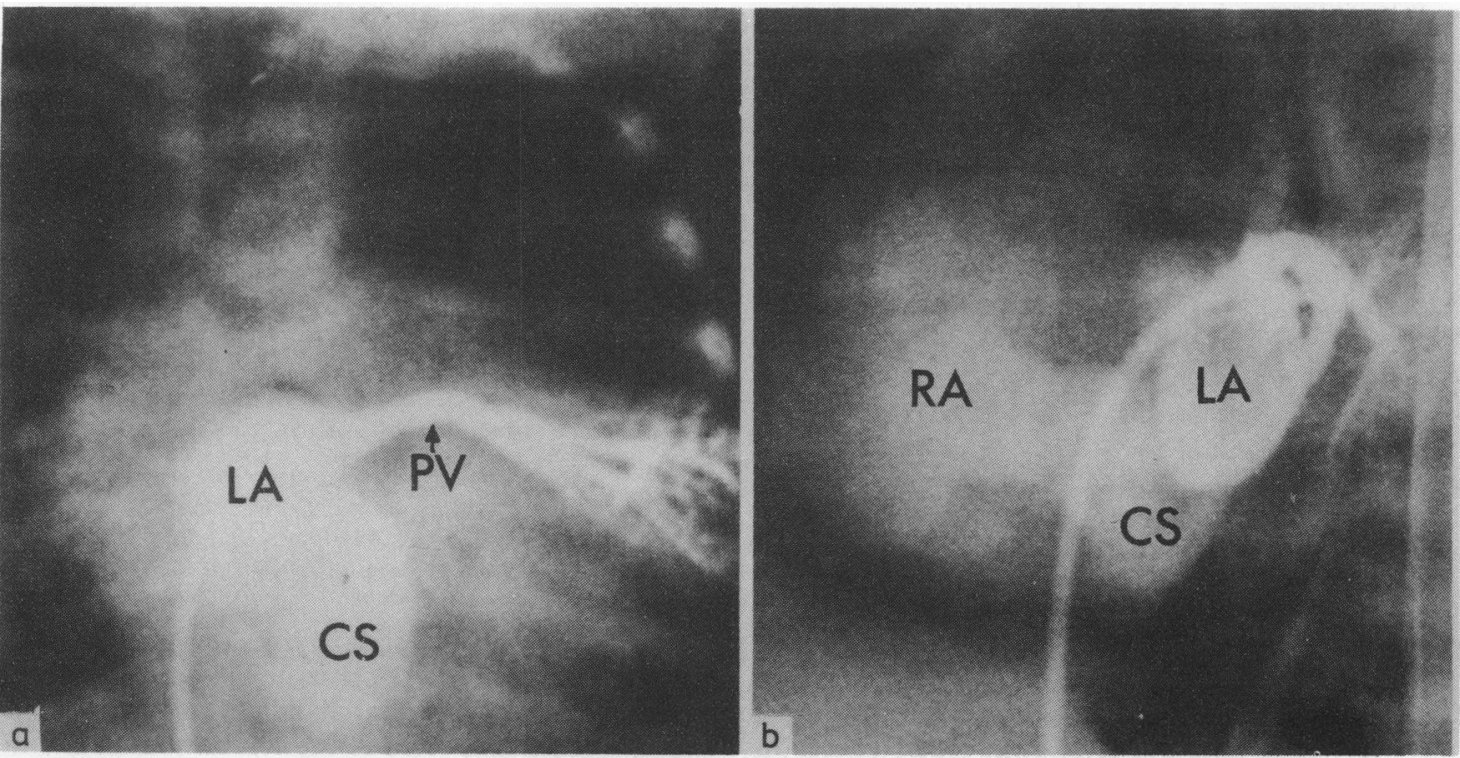

Fig. 4 Selective left pulmonary vein injection in a patient with mitral atresia, $2.0 \mathrm{~mm}$ fenestration in septum primum, and left atrial to coronary sinus window. The venous catheter has entered the left atrium through the tiny atrial septal defect. (a) The arteroposterior injection in the left pulmonary vein $(P V)$ leads to sequential opacification of the small left atrium $(L A)$ and coronary sinus $(C S)$. (b) The lateral view of this injection demonstrates the smooth floor of the left atrium consistent with mitral atresia. Passage of contrast material is from left atrium (LA) inferiorly to coronary sinus $(C S)$, and then forward to the right atrium $(R A)$. 

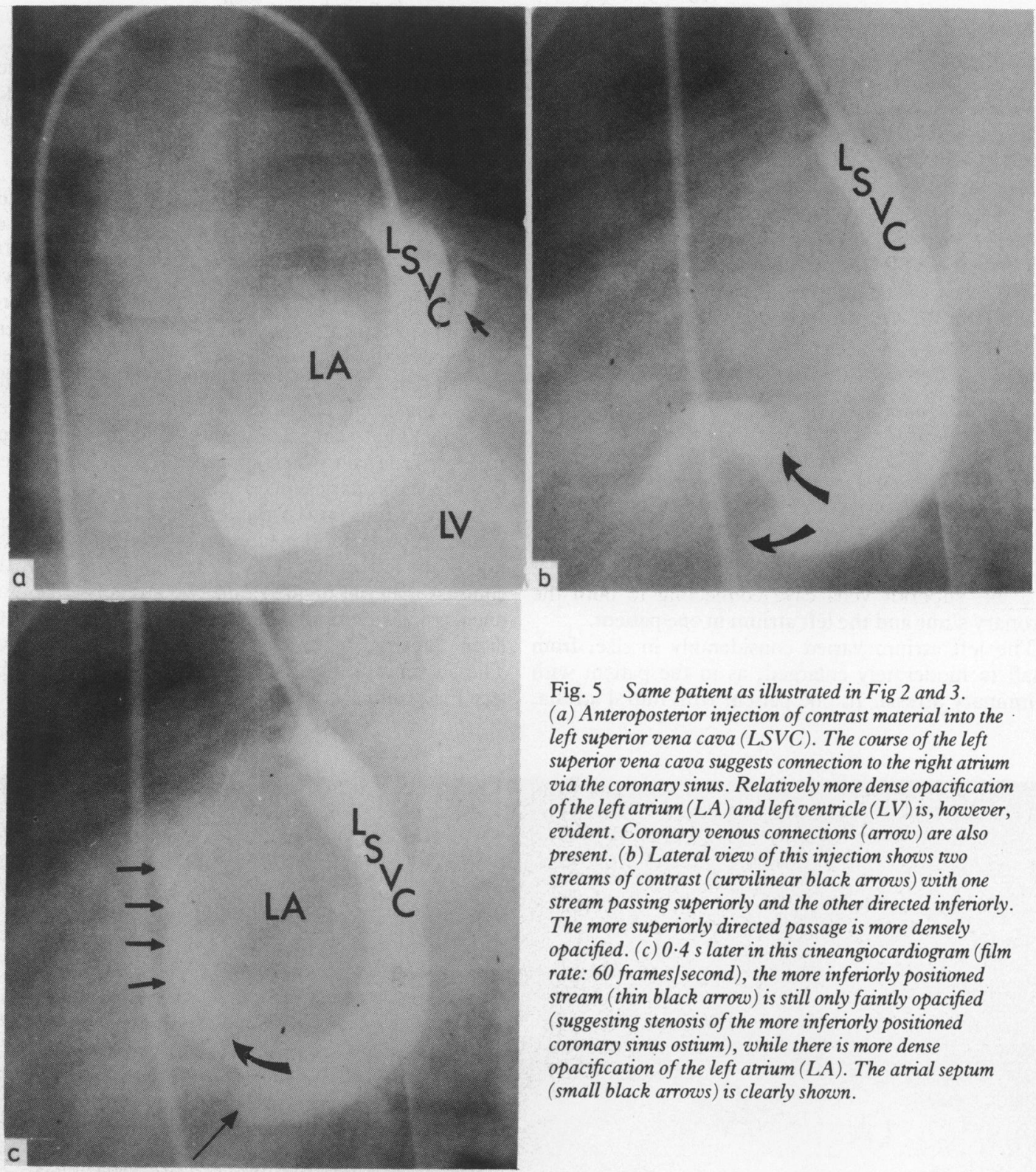

Fig. 5 Same patient as illustrated in Fig 2 and 3.

(a) Anteroposterior injection of contrast material into the left superior vena cava (LSVC). The course of the left superior vena cava suggests connection to the right atrium via the coronary sinus. Relatively more dense opacification of the left atrium ( $L A)$ and left ventricle $(L V)$ is, however, evident. Coronary venous connections (arrow) are also present. (b) Lateral view of this injection shows two streams of contrast (curvilinear black arrows) with one stream passing superiorly and the other directed inferiorly. The more superiorly directed passage is more densely opacified. (c) 0.4 s later in this cineangiocardiogram (film rate: 60 frames/second), the more inferiorly positioned stream (thin black arrow) is still only faintly opacified (suggesting stenosis of the more inferiorly positioned coronary sinus ostium), while there is more dense opacification of the left atrium (LA). The atrial septum (small black arrows) is clearly shown.

FUNCTIONAL SIGNIFICANCE OF LEFT ATRIAL TO CORONARY SINUS WINDOW

When this unusual fenestration occurs in isolation, or together with an uncomplicated atrial septal defect, the left atrial to coronary sinus window carries a left-toright shunt. ${ }^{2-4}$ 6-10 If a left superior vena cava is connected to the coronary sinus, however, systemic venous blood may be diverted to the left atrium via the fenestration, resulting in systemic desaturation. This right-

to-left shunt can be substantial if there is, in addition, atresia, stenosis, or hypoplasia of the coronary sinus ostium $^{811}$ and further augmentation may occur if an hepatic vein is connected to the coronary sinus ${ }^{12}$ with an obstructed ostium.

The presence of a left atrial to coronary sinus fenestration recently complicated complete repair in a patient thought to have an uncomplicated secundum atrial septal defect. The clinical findings, chest radio- 
graph, electrocardiogram, M-mode, and twodimensional echocardiogram were all consistent with a large left-to-right shunt through a secundum atrial septal defect. Preoperative cardiac catheterisation was therefore not deemed necessary. At the time of cardiac surgery, the secundum defect was characterised as "quite small", but the ostium of the coronary sinus was significantly enlarged. Exploration excluded anomalous systemic or pulmonary venous connections as being responsible for enlargement of the coronary sinus, and a left atrial to coronary sinus fenestration was identified. Both the atrial septal defect and the ostium of the coronary sinus were patched, and thus the coronary veins now drained to the left atrium via the window. The postoperative result was excellent, and radionuclide angiography from the left arm showed a left brachiocephalic vein connected normally to a right superior vena cava, and no evidence of intracardiac shunting.

When the atrioventricular valve is severely obstructed and when the naturally occurring atrial septal defect is small, the left atrial to coronary sinus window provides a vital route for the flow of blood. $.^{2-4} 8-10$ Thus, in situs solitus, when the left atrium is potentially "blind", the window decompresses the left atrium causing a left-to-right intracardiac shunt. The reverse should be true for the patient with a severely obstructed right-sided atrioventricular valve. One of our patients, however, had such a right atrioventricular valve but also had significant stenosis of the right atrial coronary sinus ostium, and the coronary sinus to left atrial vindow facilitated right atrial decompression by a circuitous route because of the connection of the left superior vena cava to the coronary sinus (see Fig. 2, 3, $5,6)$.

\section{Discussion}

Abnormalities of the coronary sinus are not uncommon, but before the review by Mantini from Edwards's laboratory in $1966,{ }^{3}$ such abnormalities had not been studied systematically. They include enlargement of the sinus resulting from anomalously connected systemic (hepatic or left superior vena caval veins) or pulmonary veins; absence of the sinus; atresia of its ostium; hypoplasia with direct connection of the cardiac veins to the right or left atrium, or displacement: ${ }^{1-13}$ Eight months earlier, also from Edwards's laboratory, Raghib and his colleagues described the complex characterised by termination of the left superior vena cava in the left atrium, atrial septal defect, and absence of the coronary sinus, ${ }^{1}$ the fundamental developmental abnormality being, they suggested, failure of completion of the left atriovenous fold. Given a heart with a left superior vena cava draining normally to the coronary sinus, this complex can be created by excising the entire common partition wall or roof of the coronary sinus separating it from the left atrium. ${ }^{14}$ We would endorse the view of Rose from Edwards's laboratory ${ }^{2}$ and others, ${ }^{14}$ that the relatively "isolated" fenestration between the left atrium and coronary sinus represents a forme fruste of the developmental complex described by Raghib et al. ${ }^{1}$

Alternative pathways for systemic or pulmonary venous flow in the presence of obstructive anomalies of the atrioventricular junction are uncommon, and the morphological expression of these alternative pathways has been summarised in the papers of Mantini et al., ${ }^{3}$ Beckman et al. ${ }^{4}$ Rose et al. ${ }^{2}$ and others. ${ }^{15-19}$

When the obstruction involves the left atrioventricular valve, the alternative pathways include (1) left atrial to coronary sinus window ${ }^{4}$; (2) anomalous pulmonary venous connections ${ }^{4}$; (3) the so-called laevoatriocardinal vein or other left atrial to systemic venous connection. ${ }^{15-17}$ The coronary sinus to left atrial window provides an alternative (right-to-left) pathway when there is extreme tricuspid stenosis or tricuspid atresia. Thus the same anatomical defect (coronary sinus to left atrial window) may provide either a rightto-left, or a left-to-right alternative pathway depending on which atrioventricular valve is obstructed.

When both the atrial septal defect and ostium of coronary sinus are small and cause obstruction as in our patient with pulmonary atresia, intact ventricular septum, and extreme tricuspid stenosis, the connection of the systemic venous system to the left atrium via the coronary sinus to left atrial window is of structural and functional importance. Indeed, our angiographic and haemodynamic data support the possibility that much of the venous return from the head and neck is diverted to the left superior vena cava and thence into the left atrium via the window. This pathway seems to "decompress" the right atrium.

The clinical and angiocardiographic recognition of the coronary sinus to left atrial window has more than academic merit. The recent emphasis on the morphology, diagnosis, and palliation of patients with the hypoplastic left heart syndrome ${ }^{20-29}$ necessitates a complete understanding of the haemodynamic and morphological variables including these alternative pathways. ${ }^{30} 31$ Similarly, the aggressive surgical approach to patients with pulmonary atresia and intact ventricular septum recently summarised by Moulton and his colleagues from Columbia, ${ }^{32}$ and by Patel $e t a l$. from this institution ${ }^{33}$ must be based on knowledge of real and potential circulatory pathways.

\section{References}

1 Raghib G, Ruttenberg HD, Anderson RC, Amplatz K, Adams $\mathrm{P}$ Jr, Edwards JE. Termination of left superior vena cava in left atrium, atrial septal defect and absence of coronary sinus. A developmental complex. Circulation 1965; 31: 906-18. 
2 Rose AG, Beckman CB, Edwards JE. Communication between coronary sinus and left atrium. Br Heart $\mathcal{F} 1974$; 36: 182-5.

3 Mantini E, Grondin CM, Lillehei CW, Edwards JE. Congenital anomalies involving the coronary sinus. Circulation 1966; 33: 317-27.

4 Beckman CB, Moller JH, Edwards JE. Alternate pathways to pulmonary venous flow in left sided obstructive anomalies. Circulation 1975; 52: 509-16.

5 De Leval MR, Ritter DG, McGoon DC, Danielson GK. Anomalous systemic venous connection. Surgical considerations. Mayo Clin Proc 1975; 50: 599-610.

6 Fieldstein LE, Pick J. Drainage of the coronary sinus into the left auricle. Report of a rare congenital anomaly. $A m \mathcal{F}$ Clin Pathol 1942; 12: 66-9.

7 MacMahon HE. Communication of the coronary sinus with the left atrium. Circulation 1963; 28: 947-50.

8 Goor DA, Lillehei CW. Congenital malformations of the heart. New York: Grune \& Stratton, 1975: 410-11.

9 Gould SE, ed. Pathology of the heart and blood vessels. 3rd ed. Springfield, Illinois: Charles C Thomas, 1968: 388.

10 Sherman FE. An atlas of congenital heart disease. Philadelphia: Lea \& Febiger, 1963: 67-73.

11 Kinard SA. Hypoplasia of the coronary sinus with coronary venous drainage into the left ventricle by way of the Thebesian system. Chest $1975 ; 68$ : 384-5.

12 Van der Horst RL, Winship WS, Gotsman M S. Drainage of left hepatic vein into coronary sinus associated with other systemic venous anomalies. Br Heart $\mathcal{F}$ 1971; 33: 164-6.

13 Yokoyama M, Ando M, Takao A, Sakakibara S. The location of the coronary sinus orifice in endocardial cushion defects. Am Heart f 1973; 85: 302-7.

14 Quaegebeur J, Kirklin JW, Pacifico AD, Bargeron LM Jr. Surgical experience with unroofed coronary sinus. Ann Thorac Surg 1979; 27: 418-25.

15 Edwards JE, Dushane JW. Thoracic venous anomalies. Arch Pathol 1950; 49: 517-37.

16 Lucas RV Jr, Lester RG, Lillehei CW, Edwards JE. Mitral atresia with levoatriocardinal vein. A form of congenital pulmonary venous obstruction. Am F Cardiol 1962; 9: 607-13.

17 Hunt CE, Rao S, Moller JH, Edwards JE. Anomalous pulmonary vein serving as collateral channel in aortic stenosis with hypoplastic left ventricle and endocardial fibroelastosis. Chest 1970; 57: 185-9.

18 Moreno F, Quero JM, Diaz LP. Mitral atresia with normal aortic valve. A study of eighteen cases and a review of the literature. Circulation 1976; 53: 1004-10.

19 Macartney FJ, Bain HH, Ionescu MI, Deverall PB, Scott O. Angiocardiographic/pathologic correlations in congenital mitral valve anomalies. Eur $\mathcal{F}$ Cardiol 1976; 4: 191-211.

20 Freedom RM, Williams WG, Dische MR, Rowe RD. Anatomical variants in aortic atresia. Potential candidates for ventriculoaortic reconstitution. $B r$ Heart $\mathcal{F}$ 1976; 38: 821-6.

21 Freedom RM, Dische MR, Rowe RD. Conal anatomy in aortic atresia, ventricular septal defect, and normally developed left ventricle. Am Heart $\mathcal{F}$ 1977; 94: 689-98.

22 Freedom RM, Culham JAG, Rowe RD. Aortic atresia with normal left ventricle. Distinctive angiocardiographic findings. Cathet Cardiovasc Diagn 1977; 3: 283-95.

23 Thiene G, Gallucci V, Macartney FJ, Del Torso, S, Pellegrino PA, Anderson RH. Anatomy of aortic atresia cases presenting with a ventricular septal defect. Circulation 1979; 59: 173-8.

24 Bharati S, Lev M. The conduction system in hypoplasia of the aortic tract complex. Circulation 1979; 59: 1324-32.

25 Doty DB, Knott HW. Hypoplastic left heart syndrome. Experience with an operation to establish functionally normal circulation. I Thorac Cardiovasc Surg 1977; 74: 624-30.

26 Knott HW, Doty DB. Experimental bypass of the left ventricle. F Thorac Cardiovasc Surg 1977; 74: 436-9.

27 Albert HM, Bryant LR. A proposed technique for treatment of hypoplastic left heart syndrome. $\mathcal{F}$ Cardiovasc Surg (Torino) 1978; 19: 257-60.

28 Norwood WI, Kirklin JK, Sanders SP. Hypoplastic left heart syndrome: experience with palliative surgery. $\mathrm{Am}$ f Cardiol 1980; 45: 87-91.

29 Mohri H, Horiuchi T, Haneda K, et al. Surgical treatment for hypoplastic left heart syndrome. Case reports. $\mathcal{F}$ Thorac Cardiovasc Surg 1979; 78: 223-8.

30 Bourdillon PD, Foale RA, Somerville J. Persistent left superior vena cava with coronary sinus and left atrial connections (case report). Eur F Cardiol 1980; 11: 227-34.

31 Nath PH, Delaney DJ, Zollikofer C, et al. Coronary sinusleft atrial window. Radiology 1980; 135: 319-22.

32 Moulton AL, Bowman FO Jr, Edie RN, et al. Pulmonary atresia with intact ventricular septum. Sixteen year experience. $\mathcal{F}$ Thorac Cardiovasc Surg 1979; 78: 527-36.

33 Patel RG, Freedom RM, Moes CAF, et al. Right ventricular volume determinations in 18 patients with pulmonary atresia and intact ventricular septum. Analysis of factors influencing right ventricular growth. Circulation $1980 ; 61: 428-40$.

Requests for reprints to Dr Robert M Freedom, The Hospital for Sick Children, 555 University Avenue, Toronto, Ontario, Canada M5G 1XG. 